\title{
Aplicação de filmes biodegradáveis de proteínas do soro de leite
}

\author{
Dayana Silva Batista Soares ${ }^{1}$, Estéfani Emanuele Alves do Nascimento Silva ${ }^{1}$, Taysa Martins \\ de Oliveira ${ }^{1}$ \\ ${ }^{1}$ Instituto Federal Goiano, Campus Morrinhos, Morrinhos, Goiás, Brasil. E-mail: dayana.soares@gmail.com, \\ estefani.silva@ifgoiano.edu.br, taysaamartins@gmail.com
}

Recebido: 15/04/2016; Aceito: 07/07/2016.

\section{RESUMO}

A embalagem tem como função principal manter a integridade do produto, protegendo-o contra danos mecânicos, perda e ganho de umidade. A maior parte das embalagens é fabricada com materiais não biodegradáveis e de fonte não renovável promovendo grande impacto ambiental. Já os filmes biodegradáveis vêm surgindo como alternativa viável a este problema. Os filmes biodegradáveis não apresentam a mesma resistência apresentada pelos filmes sintéticos logo, muitos tratamentos estão sendo aplicados aos filmes na tentativa de melhorar as propriedades mecânicas. Assim, foram desenvolvidos a partir do concentrado proteico de soro do leite aplicando duas variações de tratamento de pH: 5,5 e 8,5 no método de casting. Para a avaliação da embalagem avaliou-se espessura, umidade, microscopia eletrônica de varredura. Avaliou-se também a perda e o ganho de umidade das bolachas usadas para testar o desempenho da embalagem durante as 96 horas de armazenamento, sendo que a cada 24 horas era feito uma analise detectando o comportamento do filme. Verificou-se que a proteína do soro do leite é uma ótima alternativa para o desenvolvimento de filmes biodegradáveis, apresentando variação na umidade, ganho de massa devido à permeabilidade dos filmes e homogeneidade na microscopia eletrônica de varredura.

Palavras-chave: embalagens biodegradáveis; armazenamento; concentrado proteico de soro de leite.

\section{Application of biodegradable films of whey proteins}

\section{ABSTRACT}

The package's main function is to maintain the integrity of the product, protecting it against mechanical damage, loss and gain moisture. Most packaging is made of non-biodegradable material and non-renewable sources promoting great environmental impact. Thus, biodegradable films have emerged as a viable alternative to this problem. Biodegradable films did not have the same resistance presented by synthetic films, so, many treatments are being applied to films in an attempt to improve the mechanical properties. Thus they were developed from the protein concentrated whey $\mathrm{pH}$ treatment by applying two variations: 5.5 and 8.5 in the casting method. For the evaluation of the package were measured thickness, moisture, scanning electron microscopy. It was also evaluated the loss and gain moisture of the wafers used to test the performance of the packaging during the first 96 hours, and every 24 hours an analysis was made detecting the film behavior. It was found that the whey protein is a great alternative to the development of biodegradable films, with variation in moisture, weight gain due to the permeability of the films and homogeneity in scanning electron microscopy.

Key words: biodegradable containers; storage; concentrated whey protein. 


\section{Introdução}

As embalagens são de fundamental importância na comercialização dos produtos uma vez que desempenham a função básica de proteção. Além desta função, também são apoio ao marketing do produto, agregando valor a este e estimulando sua venda (ABRE, 2011). As embalagens podem ser produzidas a partir de diferentes materiais, tais como: plásticos, papel, papelão, metal e vidro. No entanto, os plásticos derivados de petróleo são utilizados na grande maioria das embalagens, sejam como filmes individuais ou combinados com outros materiais (tais como o cartão de papel e metais) (ZHAO et al., 2008). A dificuldade de reciclagem da maioria das embalagens sintéticas disponíveis tem incentivado pesquisas nacionais e internacionais no sentido de incrementar e/ou desenvolver materiais biodegradáveis com características que permitam a sua utilização em embalagens (MALI et al., 2010; AVELLA et al., 2005; NUNES et al., 2003).

Filmes biodegradáveis são películas obtidas a partir de materiais biodegradáveis e apresentam a função de proteger os produtos quanto às ações externas (KROCHTA, 2002). As proteínas do soro de leite são importantes polímeros empregados na elaboração de filmes biodegradáveis. Filmes proteicos de soro de leite apresentam um grande potencial para aplicação como embalagem, evidenciando suas propriedades mecânicas e ópticas (FERNANDES et al., 2015). Os filmes proteicos podem ser utilizados como um complemento à embalagem sintética, prolongando a vida-de-prateleira garantindo maior qualidade do produto final, além de apresentar um potencial econômico, pois sua matériaprima é de baixo custo. Porém, a natureza hidrofílica dos filmes proteicos limita a sua aplicação em produtos que requerem barreira à umidade (YOSHIDA; ANTUNES, 2009).

Muitas são as alternativas que visam melhorar as propriedades funcionais dos filmes biodegradáveis como ajuste de $\mathrm{pH}$, adição de aditivos, emprego de polímeros sintéticos biodegradáveis, irradiação, dentre outros. Em valores de $\mathrm{pH}$ acima ou abaixo do ponto isoelétrico (pI), as moléculas de proteínas possuem cargas positivas ou negativas em excesso, que interagem com as moléculas de água contribuindo para sua solubilização (SGARBIERI, 1996).

O soro de leite é um importante co-produto, gerado pelos laticínios através da caseificação, ou seja, após a coagulação da caseína, variando suas características de acordo com a qualidade do leite e tipologia de processamento (MARSHALL, 2004; SMITHERS, 2008). Atualmente, este é reconhecido como um dos mais versáteis co-produtos da indústria de alimentos e uma fonte útil de proteínas de alta qualidade nutricional e funcional (BALDISSERA et al., 2011) seja como concentrado ou isolado protéico.

Neste contexto, visou-se com este trabalho desenvolver filmes de proteínas do soro de leite com diferentes valores de $\mathrm{pH}$ bem como avaliar o efeito $\mathrm{pH}$ na eficiência da aplicação desses filmes como embalagem para biscoitos do tipo água e sal.

\section{Material e Métodos}

O experimento foi realizado no Instituto Federal Goiano - Campus Morrinhos, localizado na cidade de Morrinhos/Go. Os filmes foram obtidos através do concentrado proteico de soro de leite comercial (Lacprodan 80 com teor de proteínas de 72,22 \% e umidade relativa de $3 \%$ ), fornecido pela indústria argentina Arla Foods.

Os filmes foram produzidos pelo método de casting (FERNANDES et al., 2015). Soluções filmogênicas aquosas foram preparadas contendo $5 \%$ de proteínas, $3,75 \%$ de glicerol e $91,25 \%$ de água, havendo a total solubilização das proteínas na água destilada e posterior adição do glicerol. Em seguida, foi aquecida as soluções a $90^{\circ} \mathrm{C}$ por $30 \mathrm{~min}$ em banho-maria e resfriada em banho de gelo, até atingir temperatura ambiente. Os pH's das soluções foram ajustados para 5,5 (próximo ao ponto isoelétrico médio das proteínas do soro de leite) e 8,5, utilizando-se hidróxido de sódio ou ácido lático. Posteriormente, alíquotas de solução filmogênica foram dispersas em placas de vidro encapadas com plástico adesivo, sendo a espessura controlada pelo volume disperso em cada placa. A evaporação do solvente ocorreu pelo processo de secagem a $38^{\circ} \mathrm{C}$ em estufa, por um período de 36 horas, garantindo uma secagem lenta dos filmes.

A espessura foi determinada por meio da média dos valores de seis pontos aleatórios em diferentes segmentos dos filmes, utilizando-se micrômetro manual.

Os sistemas de embalagens, bolachas do tipo água e sal, adquiridas no comércio local, foram envasadas com os filmes biodegradáveis produzidos e seladas com auxílio da seladora à vácuo, sendo armazenadas a temperatura ambiente por 96horas. Durante o armazenamento avaliou-se as integridades das bolachas, quanto a umidade, e dos filmes (umidade, microscopia eletrônica de varredura) a cada 24horas. Todos os experimentos foram realizados em quatro repetições de cada $\mathrm{pH}$.

A umidade das bolachas e dos filmes foi determinada em estufa à temperatura de $105^{\circ} \mathrm{C}$, por 24 horas segundo AOAC (1997). Para a avaliação da estrutura dos filmes foi utilizada a Microscopia Eletrônica de Varredura (MEV) da superfície, onde as amostras foram colocadas em recipiente com sílica-gel 
( $0 \%$ UR) durante 7 dias para eliminar resíduos de umidade. As amostras foram analisadas e montadas em suporte de alumínio ou "stubs" com fita adesiva duplaface, em seguida, foram colocadas em câmara metalizadora, para serem revestidas com uma camada de ouro. A microscopia eletrônica de varredura foi realizada no microscópio eletrônico, utilizando-se um acelerador de voltagem de $2,5 \mathrm{kV}$. A análise de MEV foi realizada no laboratório Multiusuário de Microscopia de Alta Resolução (LabMic) do Instituto de Física da Universidade Federal de Goiás (Goiânia/GO).

A análise estatística dos dados foi feita por meio do programa estatístico ASSISTAT, onde foram obtidas a análise de variância (Anova) e a comparação entre as médias das análises realizadas pelo teste de Tukey ( $\mathrm{p} \leq$ $0,05)$.

\section{Resultados e Discussão}

A espessura media dos filmes com $\mathrm{pH} 8,5$ foi de $0,147 \pm 0,030 \mathrm{~mm}$, enquanto com o pH 5,5 obteve-se média de 0,157 $\pm 0,0301 \mathrm{~mm}$. Segundo Sobral (2000), controlar a espessura do filme é uma grande dificuldade, principalmente na produção tipo casting. $\mathrm{O}$ efeito de possíveis variações das propriedades, como consequência da variação da espessura dos filmes, nem sempre é considerado, mas é fundamental.

Observou-se um ganho de umidade dos biscoitos tipo água e sal durante o armazenamento nos dois $\mathrm{pH}$ estudados (Tabela 1). Tal fato deve-se alta permeabilidade ao vapor de água apresentada pelos filmes de proteínas. Filmes de proteínas do soro tem alta permeabilidade ao vapor de água devido à alta proporção de aminoácidos hidrofílicos em suas estruturas (McHUGH et al., 1994).
Os biscoitos armazenados em filmes com $\mathrm{pH}$ 5,5 apresentaram menor ganho de umidade que os biscoitos armazenados em pH 8,5, Pérez-Gago e Krochta (1999), Yoshida e Antunes (2009), observaram que a permeabilidade ao vapor de água diminui com o aumento do $\mathrm{pH}$ em filmes de mesma espessura. Porém, segundo Sobral (2000) a taxa de permeabilidade ao vapor de água diminui linearmente com o aumento da espessura dos biofilmes, fato que pôde ser observado no presente trabalho, uma vez que os filmes de $\mathrm{pH} 5,5$ apresentaram maior espessura que os filmes de $\mathrm{pH} 8,5$.

Segundo a determinação de umidade dos filmes (Tabela 1), os filmes de diferentes $\mathrm{pH}$ 's tiveram ganho de umidade durante o armazenamento. Segundo Mali et al. (2010), a presença de água, e glicerol favorece a absorção de água, devido à sua higroscopicidade. No decorrer do tempo de aplicação dos filmes, houve mudança significativa na umidade dos filmes avaliados. Tais variações podem ser explicadas pelo fato de o filme absorver umidade ambiente.

$O$ uso da microscopia eletrônica de varredura justificou-se pela necessidade de relacionar os resultados obtidos pelas análises realizadas para que possa avaliar se houve interferência da estrutura morfológica que o filme obteve durante todo o processo de elaboração e armazenamento.

Através da observação da Figura 1, notou-se a presença de micro-furos nos filmes de ambos os $\mathrm{pH}$, além de formação de grumos causados pela aglomeração da proteína nos filmes de $\mathrm{pH}$ 5,5, além de alguns resquícios de bolacha devido ao armazenamento. Em seu estudo Hermansson (1986) comprovou que a microestrutura de géis de proteína de soro de leite em pH 9,0 apresentou-se menos agregada que em $\mathrm{pH}$ 7,0, estando em concordância com o presente estudo.

Tabela 1. Valores médio de umidade (\%) de bolachas tipo água e sal e filmes biodegradáveis de proteínas do soro de leite $(\mathrm{pH} 5,5$ e 8,5) durante armazenamento de $96 \mathrm{~h}$.

\begin{tabular}{ccccc}
\hline $\begin{array}{c}\text { Tempo de Armazenamento } \\
\text { (h) }\end{array}$ & \multicolumn{2}{c}{ Umidade da bolacha (\%) } & \multicolumn{2}{c}{ Umidade dos Filmes (\%) } \\
\hline & $\mathrm{pH} 5,5$ & $\mathrm{pH} 8,5$ & $\mathrm{pH} \mathrm{5,5}$ & $\mathrm{pH} 8,5$ \\
24 & $1,457 \pm 0,113^{\mathrm{d}}$ & $1,457 \pm 0,113^{\mathrm{d}}$ & $9,204 \pm 0,936^{\mathrm{d}^{*} A^{* *}}$ & $12,729 \pm 0,343^{\mathrm{cA}}$ \\
48 & $7,768 \pm 0,075^{\mathrm{aA}}$ & $7,407 \pm 0,0,110^{\mathrm{bB}}$ & $25,978 \pm 0,039^{\mathrm{bB}}$ & $27,041 \pm 0,292^{\mathrm{aA}}$ \\
72 & $7,391 \pm 0,061^{\mathrm{bA}}$ & $7,482 \pm 0,040^{\mathrm{bA}}$ & $29,871 \pm 1,272^{\mathrm{aA}}$ & $27,358 \pm 2,468^{\mathrm{aA}}$ \\
96 & $6,359 \pm 0,081^{\mathrm{cB}}$ & $6,641 \pm 0,0,52^{\mathrm{cA}}$ & $21,739 \pm 1,484^{\mathrm{cA}}$ & $19,759 \pm 0,329^{\mathrm{bA}}$ \\
* $^{\mathrm{cA}}$ & $7,313 \pm 0,017^{\mathrm{bB}}$ & $8,168 \pm 0,236^{\mathrm{aA}}$ & $22,799 \pm 1,125^{\mathrm{cA}}$ & $23,279 \pm 0,586^{\mathrm{abA}}$ \\
\hline
\end{tabular}

diferença significativa $(\mathrm{p}<0,05)$ entre os valores de $\mathrm{pH}$, na mesmo tempo de armazenamento. 


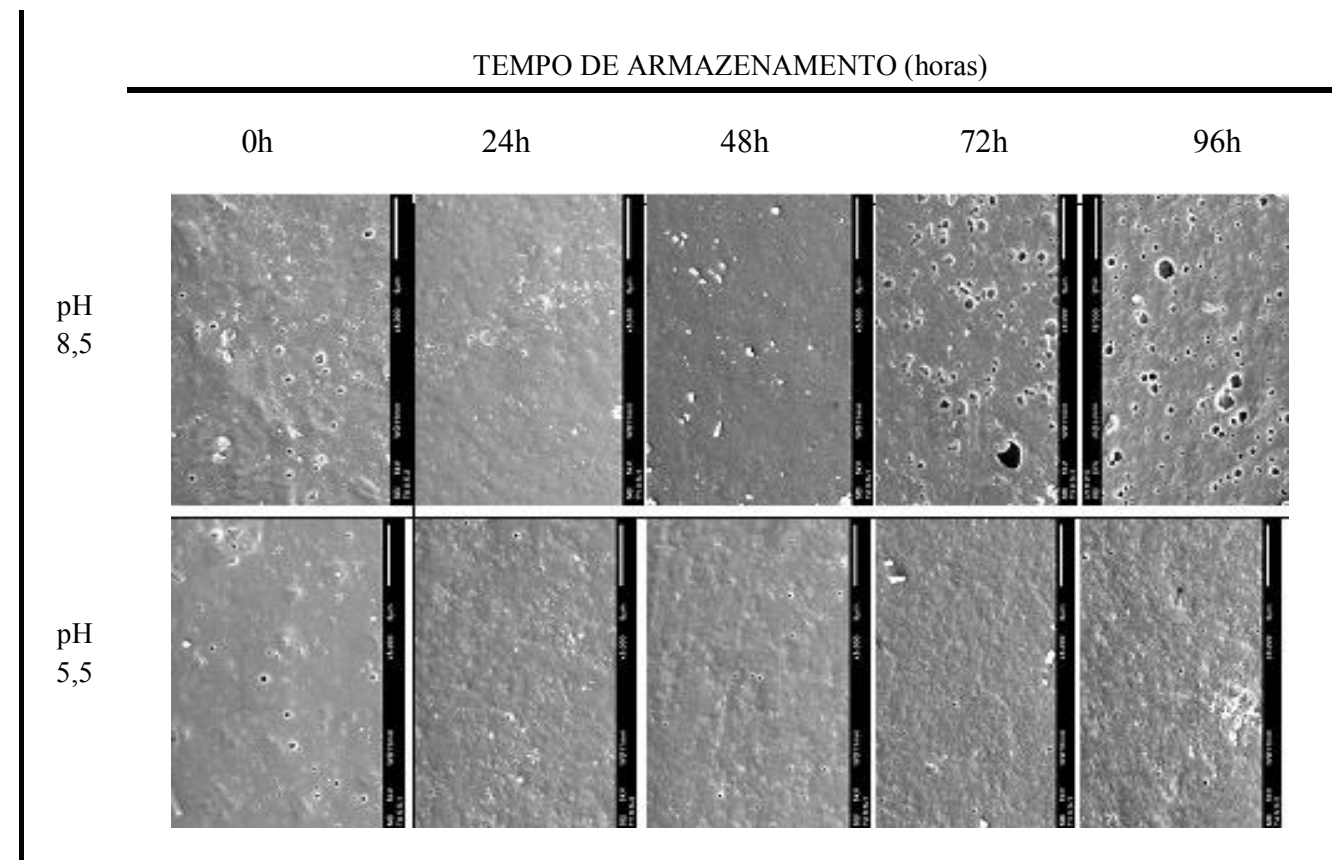

Figura 1. Microscopia Eletrônica de varredura da superfície dos filmes de acordo com tempo de armazenamento.

\section{Conclusões}

A proteína do soro do leite apresentou-se como uma boa alternativa para a elaboração de biofilmes. Observou-se que os filmes não obtiveram uma grande variação da espessura mesmo utilizando o método de casting.

Verificou-se também, variação na umidade durante o período de armazenamento dos filmes; havendo ganho de massa, que pode ter interferência com a alta permeabilidade de água que os filmes de proteína apresentam. E na microscopia eletrônica foi observado uma homogeneidade na estrutura morfológica dos filmes, apesar da presença de micro-furos em ambos $\mathrm{pH}$ e formação de grumos nos filmes de $\mathrm{pH}$ 5,5.

\section{Referências Bibliográficas}

AOAC. ASSOCIATION OF OFFICIAL ANALYTICAL CHEMISTS . Official methods of analysis: food composition, additives, natural contaminants. $16^{\mathrm{a}}$ ed. Maryland: AOAC, 1997.

ABRE. ASSOCIAÇÃO BRASILEIRA DE EMBALAGENS. Dados de mercado 2011. São Paulo-SP, 2012. Disponível em: <http://www.abre.org.br/centro_dados.php $>$. Acesso em 15 maio. 2016.

AVELLA, M., VLIEGER, J.J.; ERRICO, M.E.; FISCHER, S.; VACCA, P.; VOLPE, M.G.
Biodegradable starch/clay nanocomposite films for food packaging applications. Food Chemistry, Londres, v. 93, n. 3, p. 467-474, 2005.

BALDISSERA, A. C.; BETTA, F. D.; PENNA, A. L.; LINDNER, J. DE D. Alimentos funcionais: uma nova fronteira para o desenvolvimento de bebidas protéicas a base de soro de leite. Semina: Ciências Agrárias, Londrina-PR, v. 32, n. 4, p. 1497-1512, 2011.

FERNANDES, A. P. S.; COSTA, J. B.; SOARES, D. S. B.; MOURA, C. J. DE; SOUZA, A. R. M. DE. Application of biodegradable films produced from irradiated whey protein concentrate. Pesquisa Agropecuária Tropical, Goiânia-GO, v. 45, n. 2 , p. 192-199, 2015.

HERMANSSON, A. M. Water- and fat holding. In: MITCHELL, J. R., LEWARD, D. A. (Eds). Functional Properties of Food Macromolecule. London: Elsevier Applied Science Publishers, 1986, 348p.

KROCHTA, J. M. Protein as raw materials for films and coatings: definitions, current status, and opportunities. In: GENNADIOS, A. Protein-based films and coating. New York: CRC Press, 2002, p. 1-39, cap. 1, 2002.

MALI, S.; GROSSMANN, M. V. E.; YAMASHITA, F. Filmes de amido: produção, propriedades e potencial de utilização. Semina: Ciências Agrárias, Londrina-PR, v. 31, n. 1, p. 137-156, 2010.

MARSHALL, K. Therapeutic applications of whey protein. Alternative Medicine in Buffalo, New York, v. 9, n. 2, p. 136-156, 2004.

McHUGH, T. H.; AUJARD, F. J.; KROCHTA, J. M. Plasticized whey protein edible films: water vapor 
permeability properties. Journal of Food Science, Chicago, v. 59, n. 2, p. 416-419, 1994.

PEREZ-GAGO, M. B.; NADAUD, P.; KROCHTA, J. M. Water vapour permeability, solubility, and tensile properties of heat-denatured versus native whey protein films. Journal of Food Science, Chicago, v. 64, n. 6, p. 1034-1037, 1999.

SOBRAL, P. J. A. Influência da espessura de biofilmes feitos à base de proteínas miofibrilares sobre suas propriedades funcionais. Pesquisa Agropecuária Brasileira, Brasília-DF, v. 35 , n. 6 , p. $1251-1259,2000$.

SGARBIERI, V. Proteínas em Alimentos Protéicos: propriedades, degradação e modificação. São Paulo: Varela, 1996, p.84.
SMITHERS, G. W. Whey and whey proteins - from 'gutterto-gold'. International Dairy Journal, Alberta, v. 18, n. 7, p. 695-704, 2008

YOSHIDA, C. M. P.; ANTUNES, A. J. Aplicação de filmes protéicos à base de soro de leite. Ciência e Tecnologia de Alimentos, Campinas-SP, v. 29, n. 2, p. 420-430, 2009.

ZHAO, R. X.; TORLEY, P.; HALLEY, P. J. Emerging biodegradable materials: starch- and protein-based bionanocomposites. Journal of Materials Science, New York, v. 43, n. 9, p. 3058-3071, 2008. 